\title{
Epidemiological Study of Road Traffic Accidents in Japan during 2010-2019
}

\author{
Muhammad Husnul Khuluqi ${ }^{1} \square$ and Meily L Kurniawidjaja ${ }^{2}$ \\ ${ }^{12}$ Occupational Health and Safety Department, Faculty of Public Health, Universitas Indonesia \\ $\square$ Corresponding Author: Muhammad Husnul Khuluqi, E-mail: husnul.khuluqi@gmail.com
}

\section{ARTICLE INFORMATION}

Received: 08 October 2021

Accepted: 25 November 2021

Published: 30 November 2021

DOI: $10.32996 /$ jmhs.2021.2.2.13

\section{KEYWORDS}

Road traffic accident, Road safety, Epidemiological study, Accident severities

\section{ABSTRACT}

The study aimed to determine epidemiological characteristics of road traffic accidents in Japan during the year 2010-2019. A cross-sectional descriptive study depended on a retrospective analysis of road traffic accident data that were obtained from the National Police Agency (NPA) for the years 2010 - 2019 in Japan. The relationship of road traffic accident consequences as dependent variables with age, road user type, helmet, and seatbelt use as independent variables during the studied years was analyzed with Chi-square test. The case fatality rate has been declining every year from 3.88 in 2010 to 2.54 per 100,000 persons. More than half of fatality cases have occurred among the elderly. There was a statistically significant relationship between road user type and accident severities. $36.21 \%$ fatality occurred in pedestrians. Otherwise, $27.61 \%$ of motor vehicle occupants were dominant in serious injury cases and $66.87 \%$ in slight injury cases. Most of the casualties revealed for fatality cases were in the head, whereas the leg part was dominant in serious injury cases and the neck region was raised in slight injuries. There was a significant relationship between the use of helmets and seat belt use with casualties of road traffic accidents. There was a declined trend of road traffic accidents in Japan during 10 years of study. The result of the epidemiological study could be a valid consideration for the design of road safety policy in the future.

\section{Introduction}

Road traffic accidents and their consequences are a public health burden in both developed and developing countries (Peden \& Hyder, 2002). The mortality statistic on the world's roads remains unacceptably high, with 1.35 million people dying each year (World Health Organization, 2018). The occurrence of traffic accidents is the impact of aspects of the system consisting of roads, the environment, vehicles, and road users, as well as the interaction between these components (Mohan et al., 2006). Traffic accidents can be viewed as a system mechanism with independent variables, namely drivers, vehicles, environmental and geographical conditions, roads, and passengers, and other road users. All of these variables interact with each other in the driving scenario, which will be a road traffic accident scenario as the dependent variable (Bayam et al., 2005).

Japan is one of the safest countries based on statistics regarding road traffic accidents (Oguchi, 2016). Estimated data from the World Health Organization in 2016 concluded that as many as 4.1 deaths per 100,000 population occurred due to road traffic accidents in Japan (World Health Organization, 2018). People in Japan have been struggling to reach this safety level of road traffic accidents. Despite this, a comprehensive study of road traffic accidents seems still to be a necessary issue. The present study aimed to determine epidemiological characteristics of road traffic accidents in Japan during the years 2010-2019.

\section{Material and Method}

This was a cross-sectional descriptive study that depended on a retrospective analysis of road traffic accident statistics for the years 2010 - 2019 in Japan. The data were obtained from National Police Agency (NPA) reported by Japan prefectural police (National Police Agency, 2021), which is targeted at accidents involving fatalities or injuries caused by vehicles, streetcars, and trains on the road. The variables measured in the analysis were age, road user type, and helmet and seat belt use during the accident.

Copyright: (c) 2021 the Author(s). This article is an open access article distributed under the terms and conditions of the Creative Commons Attribution (CC-BY) 4.0 license (https://creativecommons.org/licenses/by/4.0/). Published by Al-Kindi Centre for Research and Development, London, United Kingdom. 
An independent t-test was used to compare proportions. The relationship of road traffic accident consequences as dependent variables with independent variables during the studied years was analyzed with the Chi-square test. Statistical analysis was performed using SPSS 26 software and graph visualizations were provided by Microsoft Excel and ChartBlocks.

\section{Result}

During 2010-2019, a total of 5,606,143 traffic accidents were reported where 40,011 were categorized as fatal accidents. The case fatality rate has been declining every year from 3.88 in 2010 to 2.54 per 100,000 persons. More than half of fatality cases have occurred among the elder population (65 and over) that revealed a significant difference with the under 65 groups (1,037,471; $p$ $=0.01)$. The least frequency belonged to the age group 10-14 years with 178 cases $(0.43 \%)$. The detailed trend in fatalities by age group characteristics is presented in figure 1. A significant relationship was discovered statistically between age and death or kind of injuries in road traffic accidents $(p<0.001)$.

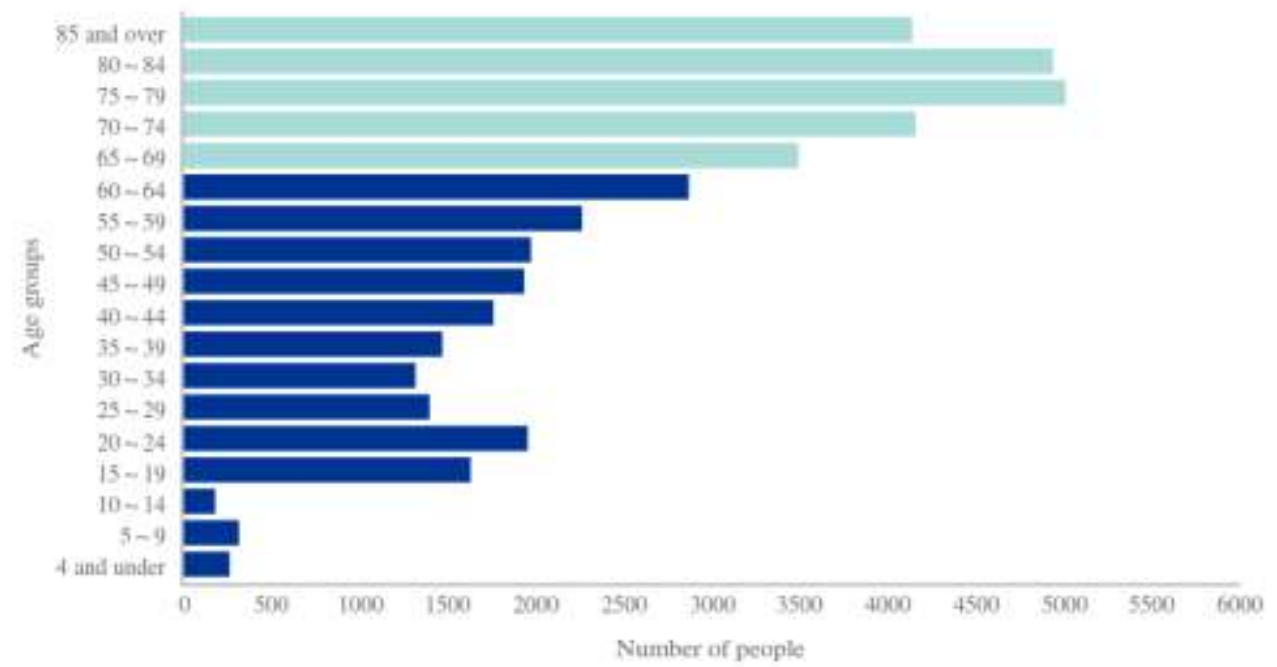

Figure 1 Trend in fatalities by age groups in the year $2010-2019$

The highest number of traffic accidents occurred in the daytime (72.97\%). Multiple vehicles cases were dominant (86.43\%) with rear-end collision as the most leading type of collision. Nevertheless, accidents involving persons and vehicles were only $10.08 \%$ with crossing the road acts as the main frequent cause. Private passenger cars were involved as the primary party in $69.52 \%$ of accidents, followed by private truck vehicles with a percentage of $13.64 \%$.

There was a statistically significant relationship between road user type and accident severities (table 1). Most fatality cases occurred in pedestrians $(14,862 ; 36.21 \%)$. Otherwise, 113,970 (27.61\%) motor vehicle occupants were dominant in serious injury cases and 4,353,543 (66.87\%) in slight injury cases.

Table 1 Frequency distribution of accident severities by road user type

\begin{tabular}{|l|l|l|l|l|}
\hline \multirow{2}{*}{ Road user type } & \multicolumn{2}{l|}{ Accident severities } & \multirow{2}{*}{ Total } \\
\cline { 2 - 4 } & Fatality & Serious accident & Slight accident & \\
\hline Motor vehicle occupant & $13,496(0.19 \%)$ & $113,970(1.64 \%)$ & $4,353,543(62.52 \%)$ & $4,481,009(64.35 \%)$ \\
\hline Motorcycle rider & $4,520(0.06 \%)$ & $54,721(0.79 \%)$ & $306,342(4.40 \%)$ & $365,583(5.25 \%)$ \\
\hline Moped 1st class rider & $2,580(0.04 \%)$ & $60,873(0.87 \%)$ & $363,853(5.23 \%)$ & $427,306(6.14 \%)$ \\
\hline Pedal cyclist & $5,461(0.08 \%)$ & $91,261(1.31 \%)$ & $1,000,158(14.36 \%)$ & $1,096,880(15.75 \%)$ \\
\hline Pedestrian & $14,862(0.21 \%)$ & $91,377(1.31 \%)$ & $478,593(6.87 \%)$ & $584,832(8.40 \%)$ \\
\hline Others & $121(0.00 \%)$ & $657(0.01 \%)$ & $7,167(0.10 \%)$ & $7,945(0.11 \%)$ \\
\hline Total & $41,040(0.59 \%)$ & $412,859(5.93 \%)$ & $6,509,656(93.48 \%)$ & $6,963,555(100 \%)$ \\
\hline$p$-value & & & & \\
\hline & $<0.001$ & & & \\
\hline
\end{tabular}




\section{Fatalities}

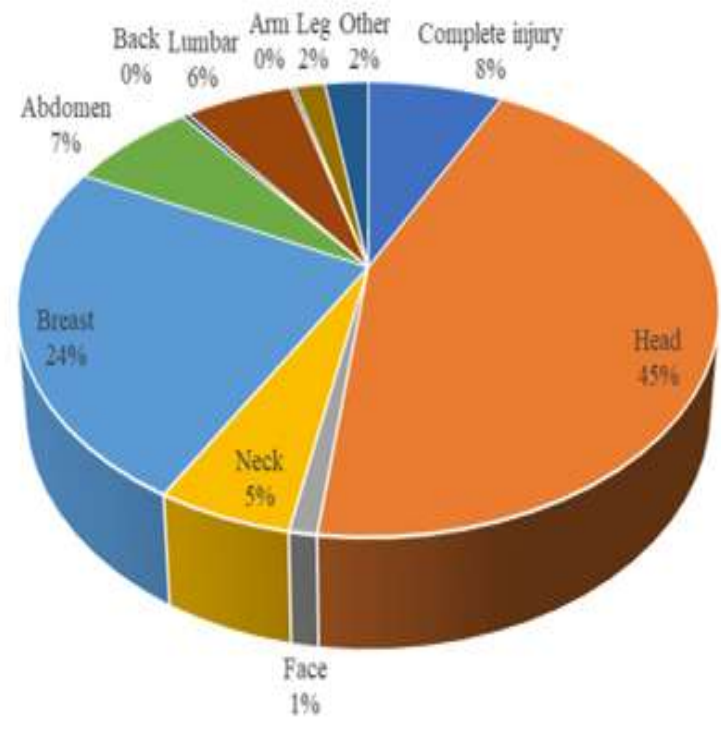

\section{Serious injuries}

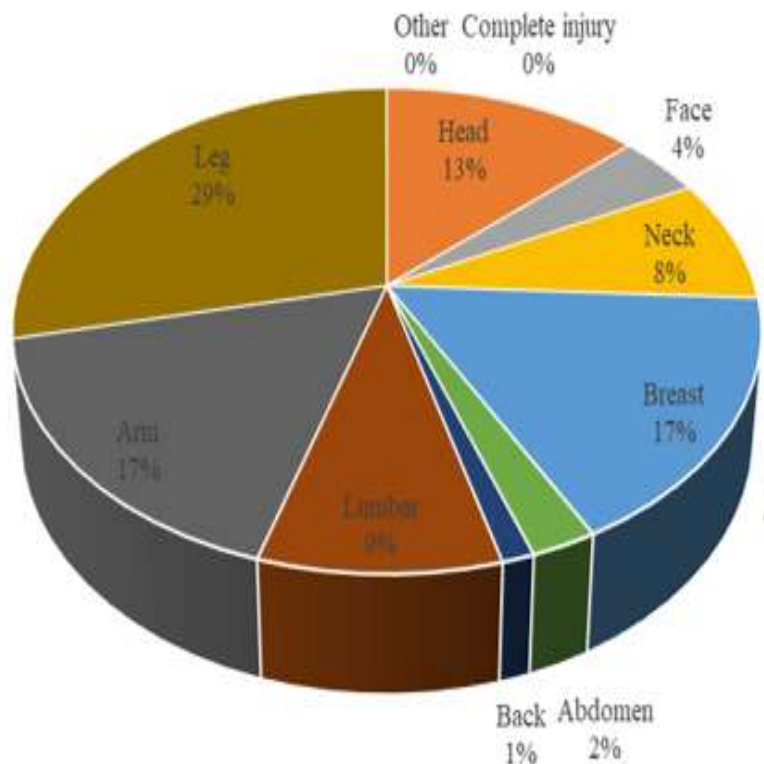

Slight injuries

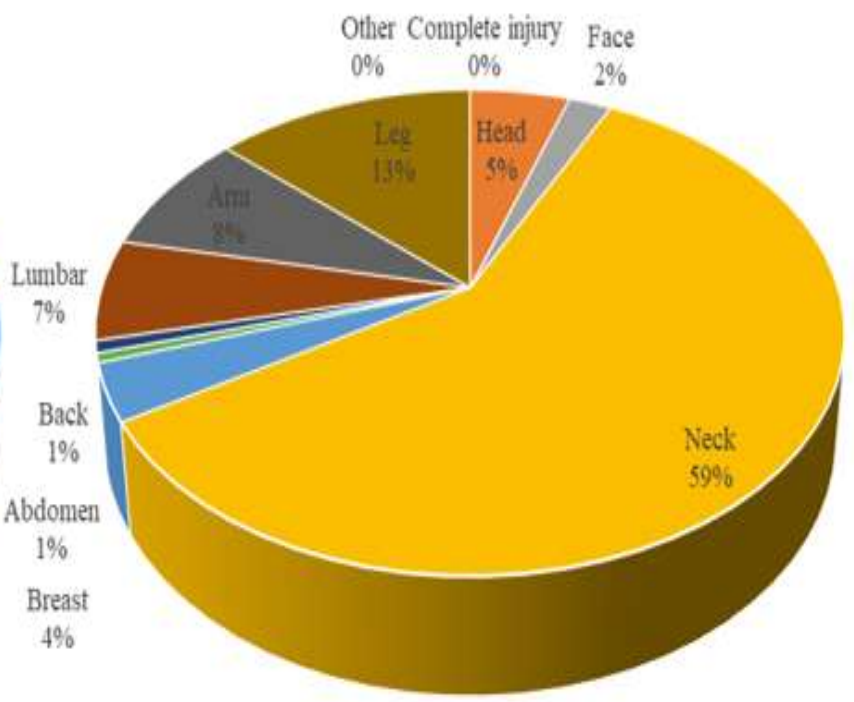

Figure 2 The major part of critical damage in road traffic casualties

Regarding the major body part of critical damage (figure 2), most of the casualties revealed for fatality cases were in the head $(18,258 ; 44.49 \%)$, whereas the leg part $(117,550 ; 28.47 \%)$ was dominant in serious injury cases and neck region $(3,839,047 ; 58.97 \%)$ raised in slight injuries.

Most motor vehicle occupants $(4,109,783 ; 91.72 \%)$ who used seat belts were suffered a slight injury and 7,923 fatality cases (0.15\%) occurred without seat belts used. Therefore, the seat belt used ratio in accident severity cases is $93.98 \%$. In consecutive, the helmet used proportion for motorcycle and moped 1st class rider were $99.07 \%$ and $98.39 \%$. On the contrary, the helmet used ratio for pedal cyclists was only $8.22 \%$ (table 2). There was a significant relationship between the use of helmets and seat belt use with casualties of road traffic accidents. 
Table 2 Frequency distribution of accident severities by the seat belt and helmet use

\begin{tabular}{|c|c|c|c|c|}
\hline \multirow{2}{*}{ Variable } & \multicolumn{3}{|c|}{ Accident severities } & \multirow{2}{*}{ Total } \\
\hline & Fatality & Serious accident & Slight accident & \\
\hline \multicolumn{5}{|l|}{$\begin{array}{l}\text { Seat belt use for motor } \\
\text { vehicle occupant }\end{array}$} \\
\hline Wearing & $7,293(0.18 \%)$ & $93,331(2.08 \%)$ & $4,109,783$ (91.72\%) & $4,211,037(93.98 \%)$ \\
\hline Not wearing & $6,656(0.15 \%)$ & $18,155(0.41 \%)$ & $220,618(4.92 \%)$ & 245,429 (5.48\%) \\
\hline Unknown & $547(0.01 \%)$ & $2,484(0.06 \%)$ & $21,512(0.48 \%)$ & $24,543(0.55 \%)$ \\
\hline Total & $15,126(0.34 \%)$ & 113,970 (2.54\%) & $4,351,913(97.12 \%)$ & $4,481,009(100 \%)$ \\
\hline$p$-value & $<0.001$ & & & \\
\hline \multicolumn{5}{|l|}{$\begin{array}{l}\text { Helmet use for a } \\
\text { motorcycle rider }\end{array}$} \\
\hline Wearing & $4,427(1.21 \%)$ & $53,958(14.76 \%)$ & 303,809 (83.10\%) & 362,194 (99.07\%) \\
\hline Not wearing & $75(0.02 \%)$ & $557(0.15 \%)$ & $1,991(0.54 \%)$ & $2,623(0.72 \%)$ \\
\hline Unknown & $18(0.00 \%)$ & $206(0.06 \%)$ & $542(0.15 \%)$ & $766(0.21 \%)$ \\
\hline Total & 4,520 (1.24\%) & $54,721(14.97 \%)$ & $306,342(83.80 \%)$ & $365,583(100 \%)$ \\
\hline$p$-value & $<0.001$ & & & \\
\hline \multicolumn{5}{|l|}{$\begin{array}{l}\text { Helmet use for moped } \\
1^{\text {st }} \text { class rider }\end{array}$} \\
\hline Wearing & $2,434(0.57 \%)$ & $59,244(13.86 \%)$ & 358,750 (83.96\%) & $420,428(98.39 \%)$ \\
\hline Not wearing & $119(0.03 \%)$ & $1,278(0.30 \%)$ & 4,191 (0.98\%) & $5,588(1.31 \%)$ \\
\hline Unknown & $27(0.01 \%)$ & $351(0.08 \%)$ & $912(0.21 \%)$ & $1,290(0.30 \%)$ \\
\hline Total & $2,580(0.60 \%)$ & $60,873(14.25 \%)$ & $363,853(85.15 \%)$ & $427,306(100 \%)$ \\
\hline$p$-value & $<0.001$ & & & \\
\hline \multicolumn{5}{|l|}{$\begin{array}{l}\text { Helmet use for pedal } \\
\text { cyclist }\end{array}$} \\
\hline Wearing & $185(0.02 \%)$ & $7,121(0.65 \%)$ & 82,909 (7.56\%) & $90,215(8.22 \%)$ \\
\hline Not wearing & $5,248(0.48 \%)$ & $83,388(7.60 \%)$ & $908,342(82.81 \%)$ & $996,978(90.89 \%)$ \\
\hline Unknown & $28(0.00 \%)$ & $752(0.07 \%)$ & $8,907(0.81 \%)$ & $9,687(0.88 \%)$ \\
\hline Total & $5,461(0.50 \%)$ & $91,261(8.32 \%)$ & $1,000,158(91.18 \%)$ & $1,096,880(100 \%)$ \\
\hline$p$-value & $<0.001$ & & & \\
\hline & & & & \\
\hline
\end{tabular}

\section{Discussion}

The result of this study generally showed that the mortality rate was decreased during a 10-year period. The mortality rate of road traffic accidents in Japan was 3.07 per 100,000 persons in 2016. It was less than 4.1, the estimated rate per 100,000 population by WHO in 2016 (World Health Organization, 2018). Moreover, the highest number of mortalities related to road traffic accidents were found among elderly people, which is natural considering Japan has the most aged population in the world (National Institute of Population and Social Security Research, 2012). The comparable findings were also reported on the study based on a nationwide hospital database in Japan (Matsuyama et al., 2018), with the value that could be twice higher than their population increase rate (Duc-Nghiem et al., 2016)n. Elderly populations were found at risk for the single-vehicle accident (Morita \& Sekine, 2018), both as a pedestrian (Matsui et al., 2013) and drivers (Morita \& Sekine, 2013). This might be due to the degradation of driving abilities and increased driving stress among older drivers (Zhao \& Yamamoto, 2021). A significant relationship was found between age and accident severities, which was consistent with this study (Mansouri Jalilian et al., 2020)(Lee et al., 2019)(Awasthi et al., 2019).

The ratio accident that occurred at day time was dominant. On the other hand, traffic safety and awareness in Japan consistently encourage people not to drive overnight and popularize reflective gear to prevent nighttime traffic accidents involving pedestrians and cyclists (Nishiuchi, 2014). The present study showed that rear-end collisions in multiple vehicle cases were dominant. Notably, adults had the highest likelihood of rear-end crashes (Bingham \& Ehsani, 2012).

This study revealed that pedestrians are more likely to result as fatal casualties than any other road user in Japan, even at lowspeed collision mechanisms (Matsui et al., 2013). Although, the rate result was lower than in the global case which pedestrians constitute $22 \%$ of all road traffic fatalities (World Health Organization, 2004). 
The most commonly affected body part by fatal road traffic accidents was an injury in the head. A similar result has been reported previously in Japan, concluding that traffic accident was the most frequent cause of traumatic brain injury (Kimura, 2003)(Norio et al., 2002). This finding was strengthened by a significant relationship finding between helmet use with road traffic accident severities, and other studies also confirmed this (Weiss, 1992). The effectiveness of helmet use policy for motorcycle users was positively found in Taiwan (Chang, 2005) and Iran (Bazargani et al., 2017). Although the ratio of it was very low in Japan, bicycle helmet use considerably could decrease the risk of head injuries (Oikawa et al., 2017).

\section{Conclusion}

In conclusion, there was a declined trend of road traffic accidents in Japan during 10 years of study. A significant difference between age groups in accident casualties resulted from a high mortality rate in elderly people. Most traffic accidents occurred in the daytime, with rear end-collision mechanisms in multiple vehicle cases, and crossing people activity in people-vehicle cases. Helmet and seat belt use was had a significant relationship with accident severities. By integrating data from National Police Agency (NPA), this study concluded that elderly people and pedestrians are at higher risk in road traffic accident cases. The result of the study could be a valid consideration for the design of road safety policy in the future.

Funding: This research received no external funding

Conflicts of Interest: The authors declare no conflict of interest

\section{References}

[1]. Awasthi, B., Raina, S., \& Verma, L. (2019). Epidemiological determinants of road traffic accidents in a largely rural hilly population. Journal of the Scientific Society, 46(3), 79. https://doi.org/10.4103/jss.jss_38_19

[2]. Bayam, E., Liebowitz, J., \& Agresti, W. (2005). Older drivers and accidents: A meta-analysis and data mining application on traffic accident data. Expert Systems with Applications, 29(3), 598-629. https://doi.org/10.1016/j.eswa.2005.04.025

[3]. Bazargani, H. S., Saadati, M., Rezapour, R., \& Abedi, L. (2017). Determinants and barriers of helmet use in Iranian motorcyclists: a systematic review. Journal of Injury and Violence Research, 9(1), 61. https://doi.org/10.5249/JIVR.V9I1.890

[4]. Bingham, C. R., \& Ehsani, J. P. (2012). The Relative Odds of Involvement in Seven Crash Configurations by Driver Age and Sex. Journal of Adolescent Health, 51(5), 484-490. https://doi.org/10.1016/J.JADOHEALTH.2012.02.012

[5]. Chang, L.-Y. (2005). Empirical Analysis of the Effectiveness of Mandated Motorcycle Helmet Use in Taiwan. Journal of the Eastern Asia Society for Transportation Studies, 6, 3629-3644. https://doi.org/10.11175/EASTS.6.3629

[6]. Duc-Nghiem, N., Hoang-Tung, N., Kojima, A., \& Kubota, H. (2016). Traffic Safety of Elderly Road User: the Global Trend and the Japanese Case. Journal of Japan Society of Civil Engineers, Ser. D3 (Infrastructure Planning and Management), 72(5), I_1249-I_1264. https://doi.org/10.2208/jscejipm.72.i_1249

[7]. Kimura, A. (2003). The current and problems for TBI ( traumatic brain injury ) patients in Japan. Keio Journal of Medicine, 52(2), $100-106$. https://doi.org/10.2302/kjm.52.100

[8]. Lee, H. H., Cho, J. S., Lim, Y. S., Hyun, S. Y., Woo, J. H., Jang, J. H., \& Yang, H. J. (2019). Relationship between age and injury severity in traffic accidents involving elderly pedestrians. Clinical and Experimental Emergency Medicine, 6(3), 235-241. https://doi.org/10.15441/ceem.18.052

[9]. Mansouri Jalilian, M., Safarpour, H., Bazyar, J., Safi-Keykaleh, M., Farahi-Ashtiani, I., \& Khorshidi, A. (2020). Epidemiology of road traffic crashes in Ilam Province, Iran, 2009-2013. BMC Research Notes, 13(1), 4-9. https://doi.org/10.1186/s13104-020-05366-x

[10]. Matsui, Y., Doi, T., Oikawa, S., \& Ando, K. (2013). Features of fatal pedestrian injuries in vehicle-to-pedestrian accidents in Japan. SAE International Journal of Transportation Safety, 1(2), 297-308. https://doi.org/10.4271/2013-01-0777

[11]. Matsuyama, T., Kitamura, T., Katayama, Y., Hirose, T., Kiguchi, T., Sado, J., Kiyohara, K., Izawa, J., Okada, N., Takebe, K., Watanabe, M., Miyamoto, Y., Yamahata, Y., \& Ohta, B. (2018). Motor vehicle accident mortality by elderly drivers in the super-aging era: A nationwide hospital-based registry in Japan. Medicine (United States), 97(38). https://doi.org/10.1097/MD.0000000000012350

[12]. Mohan, D., Tiwari, G., Khayesi, M., \& Nafukho, F. M. (2006). Road traffic injury prevention training manual. WHO Press.

[13]. Morita, K., \& Sekine, M. (2013). Analysis of Traffic Accidents Caused by Elderly Drivers Based on Numbers of Rear-End Collided. Transactions of Society of Automotive Engineers of Japan, 44(3), 903-908.

[14]. Morita, K., \& Sekine, M. (2018). Analysis of Single-Vehicle Accidents in Japan Involving Elderly Drivers. SAE International Journal of Transportation Safety, 6(1), 19-27. https://doi.org/10.4271/09-06-01-0002

[15]. National Institute of Population and Social Security Research. (2012). Population Projections for Japan (January 2012): 2011 to 2060. In National Institute of Population and Social Security Research.

[16]. National Police Agency. (2021). Traffic Accident Statistics. https://www.npa.go.jp/publications/statistics/koutsuu/toukeihyo_e.html

[17]. Nishiuchi, H. (2014). Traffic Safety Education and Awareness Activities in Japan. https://www.iatss.or.jp/common/pdf/en/iatss/composition/FY2014_Report_JP_En.pdf

[18]. Norio, N., Akira, Y., Minoru, S., Jun-ichi, O., Taturo, K., \& Tetuya, S. (2002). Epidemiology, prevention, and countermeasures against severe traumatic brain injury in Japan and abroad. Neurological Research, 24(1), 45-53. https://doi.org/10.1179/016164102101199530

[19]. Oguchi, T. (2016). Achieving safe road traffic - the experience in Japan. IATSS Research, 39(2), 110-116. https://doi.org/10.1016/j.iatssr.2016.01.003

[20]. Oikawa, S., Nakadate, H., Zhang, Y., Ueno, T., Aomura, S., \& Matsui, Y. (2017). Finite element analysis of the effectiveness of bicycle helmets in head impacts against roads. Journal of Biomechanical Science and Engineering, 12(4), 17-00175. https://doi.org/10.1299/JBSE.17-00175

[21]. Peden, M., \& Hyder, A. (2002). Road traffic injuries are a global public health problem. BMJ: British Medical Journal, $324(7346), 1153$. 
https://doi.org/10.1136/BMJ.324.7346.1153

[22]. Weiss, A. A. (1992). The effects of helmet use on the severity of head injuries in motorcycle accidents. Journal of the American Statistical Association, 87(417), 48-56. https://doi.org/10.1080/01621459.1992.10475173

[23]. World Health Organization. (2004). Pedestrian Safety: a road safety manual for decision-makers and practitioners. In WHO Publication. WHO Press. https://doi.org/10.4271/pt-112

[24]. World Health Organization. (2018). Global status report on road safety 2018. https://www.who.int/publications/i/item/9789241565684

[25]. Zhao, Y., \& Yamamoto, T. (2021). Review of Studies on Older Drivers' Behavior and Stress-Methods, Results, and Outlook. Sensors (Basel, Switzerland), 21(10). https://doi.org/10.3390/\$21103503 